\title{
A emoção e o ensino-aprendizagem em uma perspectiva histórico-cultural: uma pesquisa na educação infantil bilíngue
}

\author{
Emotion and teaching-learning from a historical-cultural perspective:
}

a research in bilingual early childhood education

Daniele Gazzotti ${ }^{1}$

Marilene Proença Rebello de Souza ${ }^{2}$

\begin{abstract}
RESUMO
$\mathrm{O}$ presente estudo investiga o desenvolvimento infantil e sua relação com as experiências emocionais vivenciadas em ambiente escolar, tendo por objetivo geral compreender criticamente o vínculo afetivo estabelecido entre educador e educando em contexto escolar sob a perspectiva históricocultural. Participam da pesquisa uma educadora e sete crianças de cinco anos de idade de escola de educação infantil bilíngue que realizam uma atividade colaborativa. A condução do processo de aprendizagem considerou o brincar e a agência como elementos mediadores e constitutivos tanto da situação escolar como dos sujeitos envolvidos na atividade, impulsionando o desenvolvimento em todas suas potencialidades: social, cognitiva, afetiva e motora.
\end{abstract}

Palavras-chave: Emoção. Brincar. Keywords: Emotion. Play. Schooling.

\begin{abstract}
This study investigates the childhood development and its relationship with emotional experiences lived in the school environment having as main objective to critically understand the role of emotion to the teaching-learning process in a historicalcultural perspective. One educator and seven five-year-old children from a bilingual early childhood school who participate in a collaborative activity participated in the research. The conduction of the learning process considered playing and agency as mediating and constitutive elements of both the school situation and the subjects involved in the activity, boosting development in all its potentialities: social, cognitive, affective and motor.
\end{abstract}

Escolarização.

\section{Introdução}

O presente estudo investiga o desenvolvimento infantil e sua relação com as experiências emocionais vivenciadas em ambiente escolar, tendo por objetivo geral compreender criticamente o vínculo afetivo estabelecido entre educador e educando em contexto escolar sob a perspectiva histórico-cultural. Para isso, investiga-se,

\footnotetext{
${ }^{1}$ Doutorado em Psicologia Escolar e do Desenvolvimento Humano, Universidade de São Paulo. Coordenadora Pedagógica da Aubrick - Escola Bilíngue Multicultural, Brasil. E-mail: danigazzotti@gmail.com.

2 Programa de Pós-graduação em Psicologia Escolar e do Desenvolvimento Humano, Universidade de São Paulo. Brasil. E-mail: mprdsouz@usp.br.
} 
especificamente, o papel da emoção na relação ensino-aprendizagem em crianças de cinco anos de idade que se envolvem fortemente com uma atividade escolar proposta e realizada de forma colaborativa, uma vez que têm a oportunidade de agir como construtoras de seu próprio conhecimento. Assim, esse artigo também compreende criticamente os vínculos afetivos que se estabelecem na escola e como tais relações vinculares podem interferir nos processos de aprendizagem e de desenvolvimento.

Para isso, parte de uma perspectiva histórico-cultural, com base nos construtos teóricos de Marx (1845/2009), Vygotsky (1926/2010; 1929/1994; 1930/1999; 1931/1999; 1933-35/2009; 1934/2008; 1935/1994; 1998), Bakhtin/Voloshínov (1929/1981) e Leontiev (1945/2009, 1972/1977) sobre o desenvolvimento humano.

A perspectiva histórico-cultural tem seus fundamentos no materialismo histórico-dialético de Marx (1845/2009), que concebe o homem como ser ativo, social e histórico que, por meio do trabalho, produz sua vida material. O movimento materialista marxista surgiu por volta de 1843, opondo-se ao idealista, que estava em evidência, o qual partia do pressuposto de que a atividade intelectual cria a realidade social. De maneira oposta, o materialismo marxista introduziu uma concepção de mundo baseada na realidade material, em que a "vida que determina a consciência" (MARX; ENGELS, 1845/2009, p. 12). Nesse viés, as relações materiais e reais da interação humana possibilitam o desenvolvimento psíquico e intelectual dos sujeitos.

Neste pensamento, Marx cunhou a ideia de atividade humana como capaz de alterar a realidade, em um movimento dialético em que, ao modificar a realidade, o homem também se modifica, transformando a si, ao meio e desenvolvendo novas possibilidades de interação humana. Para o autor, o desenvolvimento da consciência humana está intrinsecamente ligado à atividade material (real) do homem e a linguagem é o artefato mediador e constitutivo destas relações, qualificando a interação e possibilitando o desenvolvimento psicológico dos sujeitos.

Marx (1845/2009) denomina este caráter ativo e progressista da atividade humana como prática revolucionária, visto que modifica o ambiente e os próprios 
sujeitos: "A coincidência entre a alteração das circunstâncias e a atividade ou automodificação humanas só pode ser apreendida e racionalmente entendida como prática revolucionária" (idem, p. 120, grifo nosso).

Dentro desta perspectiva dialética de desenvolvimento, Vygotsky (1934/2008) postula que educação deve atuar em serviço do desenvolvimento, conduzindo-o, opondo-se às concepções interacionistas em que o indivíduo deve primeiro desenvolver-se biologicamente, para depois estar apto a aprender novas coisas. Para o autor, as vivências sociais ${ }^{3}$ e afetivas de aprendizagem possibilitam aos sujeitos o desenvolvimento, em um movimento do âmbito social para o âmbito subjetivo. Neste pensamento, a escola consolida-se como lócus importante para o desenvolvimento de zonas de desenvolvimento e de interação humana: os anos escolares são, no todo, o período ótimo para o aprendizado ${ }^{4}$ de operações que exigem consciência e controle deliberado; o aprendizado dessas operações favorece enormemente o desenvolvimento das funções psicológicas superiores enquanto ainda estão em fase de amadurecimento. Isso se aplica também ao desenvolvimento dos conceitos científicos que o aprendizado escolar apresenta à criança (VYGOTSKY, 1934/1984, p. 131).

Esta linha de pensamento desenvolve-se a partir do preceito de que os sujeitos se constituem mutuamente a partir das relações que estabelecem uns com os outros e com a realidade social. Deste modo, as funções psicológicas mais elaboradas como raciocínio, memória lógica e a argumentação são desenvolvidas a partir das relações reais entre as pessoas. Nesta perspectiva, o corpo humano nasce preparado com aparatos psicológicos e biológicos que precisam do território social para desenvolver-se, considerando a aprendizagem como guia do desenvolvimento. Neste prisma, a linguagem é de crucial importância, pois se acredita que ela colabora no estabelecimento e desenvolvimento das demais funções psicológicas superiores.

\footnotetext{
${ }^{3}$ Nesta perspectiva, a emoção é inerente às relações humanas.

${ }^{4}$ É importante ressaltar que em sua obra original, Vygotsky utiliza o termo obutchénie, do russo, que se remete a atividades realizadas tanto por aquele que ensina quanto por aquele que aprende, implicando um processo dialógico que promove a transformação mútua tanto do educador quanto do educando. Desta forma, embora a palavra aprendizado apareça em citações retiradas de suas obras traduzidas para o português, deve-se ter em mente que originalmente esse termo aproximase mais do conceito de ensino-aprendizagem.
} 
A educação, a vida escolar e as relações que os educandos ${ }^{5}$ vivenciam neste contexto histórico-cultural, portanto, funcionam como artefatos culturais mediadores das relações entre sujeitos e entre sujeito e meio social e cultural, promovendo o desenvolvimento psicológico, social e afetivo, por meio de processos de ensino-aprendizagem que transformam experiência em desenvolvimento ${ }^{6}$.

Para melhor compreender o papel da emoção nos processos de ensinoaprendizagem e no desenvolvimento humano, este artigo apresenta dois conceitos importantes: o brincar e a agência, que estão diretamente ligados a vivências emocionais intensas propiciadoras de desenvolvimento. Tais conceitos são brevemente explicados a seguir.

O conceito de brincar, apresentado neste artigo, pauta-se na perspectiva histórico-cultural na qual é considerado uma atividade unicamente humana, de papel singular no processo de constituição do sujeito, possibilitando o compartilhamento e construção de sentidos e significados sócio-culturais, bem como o surgimento de zonas de desenvolvimento proximais, promovendo novas aprendizagens e conduzindo o desenvolvimento. Além disso, compreende-se que o brincar é uma atividade lúdica que possibilita a vivência de experiências emocionais, a autorregulação do comportamento, o desenvolver do pensamento simbólico, a apreensão da realidade e da totalidade, a internalização de funções psicológicas superiores e o estabelecimento de vínculos afetivos.

Faz-se importante para este estudo compreender o papel da afetividade no brincar. Para Vygotsky (1933/2009), o brincar é a realização de desejos, de afetos generalizados. Segundo o autor, uma criança em idade pré-escolar é consciente de suas relações com os adultos e reage a essas de forma afetiva. Ainda, Vygotsky (1926/2010) destaca que as emoções compartilhadas no convívio social e, nesse mérito, no brincar, possibilitam o estabelecimento de novas relações entre o sujeito e o meio. O autor acrescenta que educação é sinônimo de transformação e as mudanças que mais promovem desenvolvimento nos educandos ocorrem quando

\footnotetext{
5 A escolha terminológica "educando" em vez de aluno foi feita para evitar a hierarquia subentendida nos termos professor e estudante, atribuindo ao processo de ensino-aprendizagem uma dimensão dialética e igualitária em que todos os sujeitos envolvidos nesta vivência ensinam, aprendem e desenvolvem-se, mutuamente.

${ }^{6}$ Faz-se importante compreender que, em uma perspectiva histórico-social, aspectos cognitivos e afetivos do desenvolvimento estão interligados e não podem ser separados.
} 
seus campos afetivos são tocados. Para ele, "são precisamente as reações emocionais que devem constituir a base do processo educativo" (VYGOTSKY, 1926/2010, p. 144).

O conceito de agência aqui apresentado envolve o protagonismo do educando, em forma de um agir intencional e crítico a partir da reflexão e observação analítica da realidade, distanciando-se de um simples protagonizar, de forma que dialoga diretamente com o conceito de práxis revolucionária de Marx.

A definição de agência na qual este estudo pauta-se envolve alguns conceitos encontrados em áreas correlatas à Psicologia Escolar, tais como Educação, Antropologia Social, Sociologia da Infância e Linguística Aplicada. Essas retratam como a participação do educando enquanto agente (aquele que age) é fundamental para o processo de ensino-aprendizagem. Muitas vezes, as pesquisas que tratam da importância da agência na educação a nomeiam como protagonismo. Porém, este termo carrega em sua semântica a diferenciação entre níveis de importância, em que o protagonista é mais importante que os demais. Em uma perspectiva histórico-cultural, acredita-se que os sujeitos constituem-se mutuamente por meio de suas interações um com o outro e com o mundo de forma que todos exercem papeis importantes, razão pela qual o termo agência faz mais sentido para explicar a complexidade e a diversidade das relações.

Ainda, o termo agência de Ahearn (2001), James (2009), Corsaro (2009), entre outros autores, relaciona-se ao agir crítica e intencionalmente a partir de um contexto histórico-cultural em que relações dialéticas e dialógicas estabelecem-se, possibilitando a transformação. Trata-se de um termo recente na área de Psicologia Escolar e Desenvolvimento Humano em uma perspectiva histórico-cultural, constituindo uma importante contribuição desta pesquisa para os estudos da área.

Este estudo sobre o papel da emoção na aprendizagem e no desenvolvimento humano surgiu a partir da reflexão sobre a experiência empírica de uma das autoras deste artigo, atuando como educadora-pesquisadora. Observou-se como as crianças que apresentam menos empatia, afinidade ou até mesmo possibilidade de proximidade com os educadores (e vice-versa) não costumam demonstrar interesse pelos conteúdos explorados em sala de aula ou não mostram um desempenho satisfatório no contexto escolar. Aspectos atitudinais 
como falta de atenção voluntária; agitação; desinteresse; desrespeito aos combinados do grupo - interferem diretamente no desenvolvimento pedagógico da criança e no envolvimento das atividades propostas.

Portanto, este estudo considera fundamental que os educadores reflitam sobre as relações interpessoais que se instauram em sala de aula, buscando transformá-las com o objetivo de proporcionar aos educandos vivências agradáveis que possibilitam o interesse para novas aprendizagens. Assim, as experiências emocionais intensas ${ }^{7}$ que serão vividas neste meio, transformarão também a relação dos alunos com o ensino-aprendizagem.

Colocando em pauta aspectos das relações humanas, faz-se importante compreender alguns termos referentes a elas, como o conceito de afetividade e emoção, cruciais para a compreensão deste estudo.

Na área da educação, Paulo Freire (1996/2015) notou a relevância das relações afetivas no ambiente escolar. Para ele, o estabelecimento de uma relação afetiva em sala de aula possibilita que os educandos superem suas posições de insegurança e de medo, assumindo papéis mais ativos em seus processos escolares.

Freire (1996/2015) pontua que os educadores devem constantemente refletir e analisar a própria prática. Ademais, não deveria haver um distanciamento epistemológico ${ }^{8}$, mas sim uma aproximação de teoria e prática no processo da formação dos educadores. Para ele, a afetividade ${ }^{9}$ é intrínseca ao processo ensino-aprendizagem e não é possível formar educadores que não a levem em consideração em suas atuações nesta função.

Este autor ressalta profundas desigualdades do nosso sistema social ao citar que pouca ou, por vezes, nenhuma atenção se dá às particularidades e aos detalhes que participam da vida dos sujeitos no dia-a-dia escolar. Objetivamente, a escola é um espaço para a formação. Em uma perspectiva marxista, histórica e dialética, todos os que compõem o contexto escolar estão em processo de constituição mútua, a partir da interação uns com os outros:

\footnotetext{
7 Destaca-se, pois, o conceito de experiência emocional intensa (perezhivanie) é conceito chave da tese que embasou este artigo.

8 Grifo do autor.

${ }^{9}$ Para Freire, a palavra afetividade diz respeito a qualidade de ter afeto, diferentemente da perspectiva de Wallon na qual afetividade diz respeito à capacidade do sujeito de afetar-se pelas situações que vivencia.
} 
Pormenores assim da cotidianidade do professor, portanto igualmente do aluno, a que quase sempre pouca ou nenhuma atenção se dá, têm na verdade um peso significativo na avaliação da experiência docente. O que importa, na formação docente, não é a repetição mecânica do gesto, este ou aquele, mas a compreensão do valor dos sentimentos, das emoções, do desejo, da insegurança a ser superada pela segurança, do medo que, ao ser "educado", vai gerando coragem. Nenhuma formação docente verdadeira pode fazer-se alheada, de um lado, do exercício da criticidade que implica a promoção da curiosidade ingênua à curiosidade epistemológica, do outro, sem o reconhecimento do valor das emoções, da sensibilidade, da afetividade, da intuição ou adivinhação (FREIRE, 1996/2015, p. 45-46, grifo meu).

Freire (1996/2015) complementa que os educadores precisam compreender seus educandos como sujeitos complexos, imbuídos de capacidade cognitiva, de emoções, sentimentos, experiências anteriores, etc. O estudioso fala sobre a importância do querer bem, de despertar a alegria no ambiente educativo e como tais aspectos são fundamentais à prática docente. Segundo ele, não há como separar a seriedade docente da afetividade, uma vez que se não há afeto, não surge o interesse dos educandos, interferindo negativamente no processo de ensinoaprendizagem.

No âmbito do tema da afetividade, Wallon (1941/1968) explica que afetividade é a capacidade humana de se afetar pelas situações vivenciadas, e a emoção é o conjunto de sensações e reações físicas e psíquicas que o sujeito vive na interação com o meio. Nesta concepção, os termos estão intrinsecamente interligados e não podem ser tratados de forma separada, pois a capacidade do sujeito de se afetar por suas vivências é o que possibilita o surgimento da emoção, enquanto o emocionar-se é uma expressão física e psíquica de um sujeito que se afeta pela situação.

Este pensamento também está presente nos estudos de Vygotsky (1926/2010) acerca dos sentimentos e dos estímulos contextuais. Para ele, dados semióticos como palavras, expressões faciais e corporais estão diretamente ligados às sensações que provocam no organismo. Ao sentir que o educador não acredita em sua capacidade de aprender, por exemplo, o educando pode assumir uma 
postura de vergonha, desapontamento, o que se transforma em sua realidade. Para o psicólogo russo:

Tudo nos permite afirmar que a emoção é de fato um sistema de reações relacionado de modo reflexo a esses ou aqueles estímulos. [...] O sentimento não surge por si só em estado normal. É sempre antecedido desse ou daquele estímulo, dessa ou daquela causa seja ela externa ou interna (A). O que nos faz ter medo ou sentir alegria é o estímulo de onde começa a resposta. Depois seguem-se várias reações reflexas, motoras, somáticas e secretórias (C) (VYGOTSKY,1926/2010, p.131).

Este artigo não pretende alegar que os educadores tenham intencionalidade de despertar um ou outro sentimento em seus alunos. De igual forma, uma fala ou expressão facial pode ser dita com a intenção de promover uma reflexão crítica e de desenvolvimento, mas pode ser compreendida pelo educando como uma privação de estímulo ou depreciação. A forma como cada sujeito compreende a realidade é única, e este é um outro conceito fundamental para a compreensão deste estudo, que será explicado mais adiante. Segundo os estudos de Vygotsky, mesmo que os sujeitos vivenciem a mesma situação, cada um a interpreta sob sua própria perspectiva.

Nesse pensamento, compreende-se que, na interação com o educador, um estímulo que motiva e valoriza pode despertar no educando tais sentimentos, atuando como um incentivo a continuar se desenvolvendo nas diversas situações de ensino-aprendizagem. Pelo contrário, estímulos que desmotivam, diminuem ou reduzem a confiança e a crença dos educandos em suas possibilidades, podem leválos a apresentar uma participação menos ativa em sala de aula, perdendo oportunidades de desenvolvimento.

Ainda, em ambientes escolares, é comum que os educadores entrem em contato com informações a respeito dos educandos antes de sequer conhecê-los, o que acaba interferindo em sua percepção a respeito deles. Os estudantes acabam sendo rotulados de difíceis, agitados, agressivos, desconsiderando o fato de que cada sujeito estabelece uma relação única com as pessoas e a percepção de um educador sobre o educando não pode defini-lo como sujeito.

A cultura de "reputação escolar" obnubila a percepção do educador em relação ao educando e, como resultado, limita suas possibilidades de constante 
crescimento e desenvolvimento. Deste modo, este estudo reitera a importância de que os educadores - os pares mais experientes da relação educador-educando encontrem os potenciais individuais de cada um, de maneira a romper com estereótipos pré-estabelecidos e permitir que as crianças possam ir além de suas possibilidades imediatas.

Nesta perspectiva, Almeida acrescenta:

Portanto, cabe ao educador canalizar a afetividade para produzir conhecimento [...] reconhecer o clima afetivo e aproveitá-lo na rotina diária da sala de aula para provocar o interesse do aluno (ALMEIDA, 2004, p. 126).

Concordando com tal visão de emoção e afetividade e de como elas participam das relações humanas em todas as instâncias, este artigo compreende que o investimento realizado pelo educador nas relações interpessoais são cruciais para o desenvolvimento dos seus educandos.

$\mathrm{Na}$ perspectiva vygotskiana deste artigo, o contexto exerce importante papel na constituição dos sujeitos. Nesse pensamento, Vygotsky (1934/1994) destaca a emoção como fator crucial para a constituição psicológica dos indivíduos. Para este autor, a emoção funciona como um filtro que compõe a unidade dinâmica da consciência dos sujeitos, possibilitando diferentes interpretações de uma mesma realidade. Compreende-se, então, que não somente o ambiente, mas também as emoções vivenciadas nas interações colaboram nos desenvolvimentos psicológicos dos sujeitos.

O autor apresenta o conceito de perezhivanie que, em português, poderia ser traduzido por vivência. Este conceito considera a emoção como um fator fundamental que possibilita diferentes acepções da realidade. Esta vivência/experiência explica como é possível diferentes pessoas interpretarem a mesma situação de maneira diferente.

Vygotsky (1934) esclarece que quando o sujeito interage com os outros sujeitos e com os significados sociais já construídos ao longo da existência humana, ele atribui um sentido àquele significado social, a partir de sua vivência. É dessa forma que se pode compreender como dois sujeitos podem vivenciar a mesma realidade, porém apreendê-la de maneira diferente. Para o autor, pensamento e 
emoção devem ser compreendidos juntos, visto que existe uma base afetivo-volitiva dos processos psicológicos. Neste pensamento, a emoção funciona como um instrumento mediador psicológico que auxilia no desenvolvimento de outras funções psicológicas, da mesma maneira que a linguagem serve de base para o desenvolvimento das funções psicológicas superiores. No construto teórico do psicólogo russo, ambiente e emoções colaboram no desenvolvimento psicológico infantil:

A experiência emocional [perezhivanie] que surge de qualquer situação ou de qualquer aspecto do ambiente determina que tipo de influência esta situação ou este ambiente terá na criança. Portanto, não é qualquer um dos fatores presentes neles (se analisado sem referência a criança) que determina como irá influenciar o curso de seu desenvolvimento, mas os mesmos fatores refratados pelo prisma da experiência emocional da criança [perezhivanie (VYGOTSKY, 1935b/1994, s/n, tradução nossa).

Para Vygotsky (1935b/1994) a perezhivanie consiste em uma unidade inseparável da consciência que carrega em si fatores externos e internos ao indivíduo, pois, ao mesmo tempo, essa unidade contempla a representação do ambiente (externo) e como o indivíduo experiência este ambiente (interno). Portanto, toda vivência do sujeito na sociedade e na cultura necessariamente suscitam características individuais e contextuais que só são configuradas da maneira que são no momento em que são vividas juntas.

Assim, Vygotsky atribui a perezhivanie papel fundamental para a compreensão da totalidade pelo sujeito, na forma como este compreende e vivencia a realidade, levando à formação de sua personalidade.

Desse modo, possibilita-se crer que se o educador observar analiticamente as relações reais estabelecidas no ambiente escolar, considerando a emoção como o filtro com o qual cada sujeito percebe e apreende a realidade, ele poderá, intencionalmente, promover o estabelecimento de vínculos afetivos e ou atividades que envolva a emoção dos educandos, impulsionando o desenvolvimento de todos os envolvidos na situação educativa. Em especial, os vínculos afetivos estabelecidos em uma nova e mais democrática relação escolar apontam para o desenvolvimento de sujeitos crítico-reflexivos e autônomos. 
Este artigo compreende que o brincar e a agência são, ao mesmo tempo, ferramentas importantes e inerentes ao processo de ensino-aprendizagem uma vez que constituem experiências emocionais intensas.

Compreende-se, então, que em seu construto teórico, Vygotsky propõe uma união entre aspectos sociais, culturais, históricos, cognitivos e afetivos. Em suas pesquisas, o desenvolvimento é possibilitado a partir de um processo dinâmico composto por processos sócio-afetivo-cognitivos e fatores subjetivos e contextuais (ambientais), por meio de relações dialéticas e transformativas que são mediadas pela linguagem e a afetividade, ambas constitutivas e mediadoras das relações e da mente humana, simultaneamente.

\section{A pesquisa}

A dimensão empírica desta pesquisa realiza-se por uma educadora que estabelece o vínculo pedagógico, bem como de pesquisa com seu grupo de estudantes em uma sala de aula de escola bilíngue de Educação Infantil. Com a articulação da experiência empírica da educadora-pesquisadora, pesquisa teórica e investigação em campo, este estudo configura-se como uma pesquisa qualitativa inspirada nos pressupostos da pesquisa ação e da pesquisa participante (THIOLLENT, 1947/2009 e BRANDÃO, 2007). Deste modo, apresenta-se como uma modalidade de pesquisa militante, que advoga ideais de uma sociedade mais justa e igualitária, em que sujeitos possam respeitar e tolerar as diferenças e as opiniões.

Neste pensamento, por meio da ação e da participação, esta investigação defende a possibilidade do estabelecimento de relações interpessoais nas quais o diálogo, a argumentação, a reflexão crítica e a expressão pessoal são valorizados. Apresenta aspectos de uma pesquisa ação que interfere diretamente na realidade por ser realizada pelos próprios sujeitos do contexto pesquisado:

A pesquisa-ação é um tipo de pesquisa social que é concebida e realizada em estreita associação com uma ação ou com a resolução de um problema coletivo e no qual os pesquisadores e os participantes representativos da situação da realidade a ser investigada estão envolvidos de modo cooperativo e participativo (THIOLLENT 1947/2009, p.14). 
A educadora-pesquisadora dos sujeitos participantes desta pesquisa estabeleceu uma relação com seus educandos ao longo de um ano letivo, de modo que os dados que foram analisados consistem em uma fração de diversas situações de ensino-aprendizagem. Por esta razão, as vivências emocionais com o grupo de estudantes envolvidos qualificam a pesquisa, entrelaçada ao referencial teórico.

O dado selecionado para a análise neste artigo constitui uma atividade do tipo "roda de conversa" atividade comum às práticas de educação infantil. A roda de conversa que foi escolhida como dado a ser analisado foi realizada de forma colaborativa, de modo que os educandos compartilham suas ideias, opiniões e sugestões que são aceitas pela educadora; opondo-se às práticas pedagógicas que centram a organização da proposta somente no educador.

A roda de conversa referida teve como assunto os combinados e o estabelecimento de regras a respeito de uma brincadeira que aconteceria em seguida da discussão. No trecho analisado, o grupo estava decidindo qual seria o menu do restaurante em relação ao material que tinham em mãos para a tomada de decisão. Por exemplo, em um determinado momento da discussão, decidiu-se que a lã amarela seria macarrão, enquanto a lã vermelha seria macarrão com molho de tomate.

Como parte do planejamento da série de atividades, utiliza-se como abordagem metodológica a Atividade Social, abordagem metodológica desenvolvida por Liberali (2009), baseada na Teoria da Atividade Sócio Histórico Cultural, que utiliza a língua como ferramenta-e-resultado do próprio resultado do trabalho. Utiliza performances de atividades reais dos contextos dos participantes para o aprendizado dos elementos sociais, culturais e linguísticos. O fato de o dado analisado para a pesquisa fazer parte da vida diária escolar é fundamental pois se evidencia como a interação entre todos os sujeitos do contexto escolar (educandos entre si e educandos com educadora) podem promover o desenvolvimento, uma vez que o brincar e a agência são ferramentas-e-resultados do próprio processo de ensino-aprendizagem. 
Neste caso, o objetivo era estudar a temática Going to the Restaurant (Ir ao Restaurante) e esse tema estava pré-determinado pelo currículo ${ }^{10}$ da escola. Com isso, a educadora-pesquisadora planejou a atividade de modo a promover a agência dos educandos e utilizar a construção conjunta e colaborativa de conhecimento no brincar, uma vez que o conteúdo havia sido escolhido pela escola e pelo currículo. Em sua proposta, a educadora-pesquisadora agiu de forma colaborativa, compartilhando sentidos e significados construídos em conjunto com o grupo, acolhendo as idéias e sugestões dos participantes, promovendo a agência infantil.

Os participantes da investigação são sete crianças e cinco anos de idade que estudam em escola bilíngue de São Paulo e a educadora-pesquisadora. Os educandos participantes estavam de acordo com a rotina escolar, e não houve uma razão específica para a escolha destes educandos. Para a obtenção dos dados, a educadora-pesquisadora deixou um tablet filmando a proposta e, posteriormente, assistiu, delimitou o tempo inicial e final da análise para então analisar e interpretar os dados.

\section{Quadro 1: Excerto - turnos linguísticos}

No Turno

Transcrição Linguística

\begin{tabular}{lll}
\hline 1 & E-P11 & What material do you think this could be in our restaurant? \\
& & $\begin{array}{l}\text { Tradução: Que material vocês acham que isso poderia ser em nosso } \\
\text { restaurante? }\end{array}$ \\
\hline 2 & Noé & Salad! \\
& & Tradução: Salada! \\
\hline 3 & E-P & Great! So, this will be the salad. Do you want to see the others? \\
& & Tradução: Ótimo. Então, isso será a salada. Vocês querem ver o restante? \\
\hline 4 & Alguém & Yes! \\
& & Tradução: Sim! \\
\hline
\end{tabular}

${ }^{10}$ De acordo com a Base Curricular Comum da Educação Infantil de 2018, os conteúdos da educação infantil devem abranger os seguintes campos de experiência: (i) o eu, o outro e o nós; (ii) corpo, gestos e movimento; (iii) traços, sons, cores e imagens; (iv) escuta, fala, linguagem, pensamento e (iv) espaços, tempos, quantidades e transformações. A escola em questão adota as dramatizações de situações sociais para abordar os campos (i) e (iv).

11 E-P: Educadora-pesquisadora. 


\begin{tabular}{|c|c|c|}
\hline 5 & E-P & $\begin{array}{l}\text { What material do you think this could be in our restaurant? } \\
\text { Tradução: Que material vocês acham que isso poderia ser em nosso } \\
\text { restaurante? }\end{array}$ \\
\hline 6 & E-P & $\begin{array}{l}\text { Open the circle, please? } \\
\text { Tradução: Abram a roda, por favor. }\end{array}$ \\
\hline 7 & Noé & $\begin{array}{l}\text { Spaghetti! } \\
\text { Tradução: Que material vocês acham que isso poderia ser em nosso } \\
\text { restaurante? }\end{array}$ \\
\hline 8 & Mariana & $\begin{array}{l}\text { Spaghetti! } \\
\text { Tradução: Espaguete. }\end{array}$ \\
\hline 9 & E-P & $\begin{array}{l}\text { Spaghetti! } \\
\text { Tradução: Espaguete. }\end{array}$ \\
\hline 10 & Rosa & $\begin{array}{l}\text { Spaghetti no is this color. } \\
\text { Tradução: Espaguete não é desta cor. }\end{array}$ \\
\hline 11 & E-P & $\begin{array}{l}\text { So what do we do, then? What do you think we can...? } \\
\text { Tradução: Então o que fazemos? O que vocês acham que podemos...? }\end{array}$ \\
\hline 12 & Noé & Pimenta! \\
\hline 13 & E-P & $\begin{array}{l}\text { This could be spaghetti with pepper? } \\
\text { Tradução: Isso poderia ser espaguete com pimenta? }\end{array}$ \\
\hline 14 & Noé & Ketchup! \\
\hline 15 & E-P & $\begin{array}{l}\text { This could be spaghetti with ketchup? } \\
\text { Tradução: Isso poderia ser espaguete com ketchup? }\end{array}$ \\
\hline 16 & Mariana & $\begin{array}{l}\text { Nooooooo. } \\
\text { Tradução: Não. }\end{array}$ \\
\hline 17 & Vitor & $\begin{array}{l}\text { With ketchup. } \\
\text { Tradução: Com ketchup }\end{array}$ \\
\hline 18 & E-P & $\begin{array}{l}\text { What do you think, Mariana? } \\
\text { Tradução: O que você acha, Mariana? }\end{array}$ \\
\hline 19 & Mariana & Molho de tomate \\
\hline 20 & E-P & $\begin{array}{l}\text { How do you say that in English? } \\
\text { Tradução: Como dizemos isso em inglês? }\end{array}$ \\
\hline 21 & Maria & Tomate. \\
\hline 22 & Noé & Ketchup. \\
\hline 23 & E-P & Tomato...? \\
\hline
\end{tabular}




\begin{tabular}{|c|c|c|}
\hline & & Tradução: Tomate...? \\
\hline \multirow[t]{2}{*}{24} & Roberto & Tomato sauce. \\
\hline & & Tradução: Molho de tomate. \\
\hline \multirow[t]{2}{*}{25} & E-P & Tomato sauce or ketchup. And this one? What kind would this one be? \\
\hline & & $\begin{array}{l}\text { Tradução: Molho de tomate ou ketchup. E este aqui? Que tipo este aqui } \\
\text { seria? }\end{array}$ \\
\hline \multirow[t]{2}{*}{26} & Noé & Tomato sauce! \\
\hline & & Tradução: Molho de tomate! \\
\hline \multirow[t]{2}{*}{27} & Rosa & Tomato branco! \\
\hline & & Tradução: Tomate branco! \\
\hline \multirow[t]{2}{*}{28} & Mariana & Tomato branco! \\
\hline & & Tradução: Tomate brancp! \\
\hline 29 & Rosa & Não, pode ser macarrão com molho branco. \\
\hline \multirow[t]{2}{*}{30} & E-P & This or this? \\
\hline & & Tradução: Este ou este? \\
\hline \multirow[t]{2}{*}{31} & Mariana & Mas é branco this. \\
\hline & & Tradução: Mas este é branco. \\
\hline & E-P & Look, Mariana found one that is already white. Right, Mariana? \\
\hline & & $\begin{array}{l}\text { Tradução: Vejam, Mariana encontrou um material que já é branco. Certo, } \\
\text { Mariana? }\end{array}$ \\
\hline \multirow[t]{2}{*}{33} & Mariana & Yes. \\
\hline & & Tradução: Sim. \\
\hline & Hugo & This is yellow. Olha teacher, more salad. \\
\hline & & Tradução: Este é amarelo. Olha, professora. Mais salada. \\
\hline & E-P & Hugo, I want you to be at the circle. \\
\hline & & Tradução: Hugo, eu quero que você venha para a roda. \\
\hline & E-P & Ok guys, deal. Do you want to see the rest of the material? \\
\hline & & $\begin{array}{l}\text { Tradução: Tudo bem pessoal, combinado. Vocês querem ver o restante do } \\
\text { material? }\end{array}$ \\
\hline \multirow[t]{2}{*}{37} & Crianças & Yes! \\
\hline & & Tradução: Sim. \\
\hline \multirow[t]{2}{*}{38} & E-P & So let me see who is ready... \\
\hline & & Tradução: Então deixem-me ver quem está pronto.... \\
\hline
\end{tabular}




\begin{tabular}{|c|c|c|}
\hline & & Tradução: O canudo! \\
\hline \multirow[t]{2}{*}{40} & Rosa & Macarroni! \\
\hline & & Tradução: Macarrão! \\
\hline \multirow[t]{2}{*}{41} & Hugo & Eu, eu, eu, mãe? Ana, Ana, Ana, esta é a minha mãe. \\
\hline & Tempo 1'30 & \\
\hline \multirow[t]{2}{*}{42} & Rosa & This is macaroni, macaroni. \\
\hline & & Tradução: Este é macarrão, macarrão. \\
\hline \multirow[t]{2}{*}{43} & E-P & But Rosa, we already have 3 kinds of spaghetti. What could this be? \\
\hline & & $\begin{array}{l}\text { Tradução: Mas Rosa, nós já temos três tipos de espagueti. O que isto poderia } \\
\text { ser? }\end{array}$ \\
\hline 44 & Hugo & Canudo, canudo! \\
\hline \multirow[t]{2}{*}{45} & E-P & $\begin{array}{l}\text { Yes, this is a straw! But in the game, it is something else. Use your } \\
\text { imagination. }\end{array}$ \\
\hline & & $\begin{array}{l}\text { Tradução: Sim, isso é um canudinho. Mas na brincadeira, é outra coisa. Use } \\
\text { a imaginação. }\end{array}$ \\
\hline \multirow[t]{2}{*}{46} & Noé & Spaghetti! \\
\hline & & Tradução: Espaguete! \\
\hline \multirow[t]{2}{*}{47} & E-P & We already have spaghetti Noé. \\
\hline & & Tradução: Nós já temos espaguete, Noé. \\
\hline 48 & Mariana & Canudo, canudo. \\
\hline \multirow[t]{2}{*}{49} & E-P & $\begin{array}{l}\text { It could be the straw for the juice? Yes, it could be. But what if it could be } \\
\text { something we eat? }\end{array}$ \\
\hline & & $\begin{array}{l}\text { Tradução: Poderia ser o canudinho para o suco? Sim, poderia. Mas e se fosse } \\
\text { algo de comer? }\end{array}$ \\
\hline \multirow[t]{2}{*}{50} & Vitor & I know! \\
\hline & & Tradução:Já sei! \\
\hline
\end{tabular}

$\mathrm{Na}$ interpretação e análise dos dados, observou-se que a maioria dos participantes envolvem-se de maneira satisfatória, mantendo-se concentrada na discussão e demonstrando desejo em contribuir com ideias e sugestões.

Os resultados obtidos da análise e interpretação apontam para o fato de que o envolvimento dos educandos aumenta conforme a oportunidade da agência no momento da construção dos sentidos e significados dos materiais para o brincar. É importante ressaltar que o excerto apresenta aspectos complexos e criativos evidenciados na análise linguística dos turnos. A qualidade dessas respostas das 
crianças são resultado direto da abordagem escolhida pela educadorapesquisadora, a qual questiona as crianças em vez de informá-las, conferindo a elas a oportunidade de refletir e criar. $\mathrm{O}$ envolvimento dos educandos com a atividade é altamente afetivo, uma vez que participam ativamente, em vez de agirem como meros receptores do conhecimento. Mais uma vez, reitera-se aqui a relação entre a afetividade e a agência, uma vez que a atividade escolar constitui-se em uma experiência emocional rica e significativa, que colabora na constituição dos estudantes enquanto sujeitos histórico-culturais.

No excerto escolhido para análise, os significados foram construídos em grupo e as crianças tiveram a oportunidade de negociar sentidos e significados. Os materiais não estavam pré-definidos, conforme explicado anteriormente, mas as crianças tinham a possibilidade de criar, tornando-se agentes dos próprios processos de ensino-aprendizagem, envolvendo-se na atividade e vivenciando experiências emocionais intensas proporcionadas pela educadora-pesquisadora.

De acordo com a experiência empírica da educadora-pesquisadora, no momento em que a criança percebe que é ouvida e valorizada, ela é estimulada a continuar participando e se envolvendo, transformando a relação com a aprendizagem. Desse modo, as emoções vivenciadas no contexto escolar afetam e medeiam seu processo de apreensão da realidade, constituindo assim uma unidade dinâmica de apreensão da totalidade. A participação ativa possibilita um movimento constante de questionamento a si próprio e ao outro, em que a argumentação se faz presente todo o tempo, conferindo à situação um caráter emocional importante. Então, relacionam-se as situações vivenciadas no contexto escolar - que é um importante contexto de constituição e desenvolvimento destes educandos - ao conceito de perezhivanie, de Vygotsky. As vivências afetivas e emocionais das crianças, neste ambiente de aprendizagem, impulsionam o desenvolvimento, produzindo novos significados e sentidos em suas relações com a realidade.

A relação entre educador e educando se constrói a partir de aspectos afetivos visto que, na abordagem escolhida pela educadora-pesquisadora que desenvolveu esta pesquisa, o educador precisará rever práticas em que comparece como único detentor do conhecimento, como acontece com algumas abordagens 
tradicionais de ensino-aprendizagem. A modificação estabelecida na relação de aprendizagem, bem como a vivência de emoções que reafirmam a compreensão do lugar de saber do educando, possibilita um processo ensino-aprendizagem promotor de desenvolvimento.

Em uma perspectiva histórico-cultural, a criança desenvolve as funções psicológicas superiores a partir das relações que estabelece com os sujeitos e com os objetos da cultura, tendo a linguagem e a emoção como instrumentos constitutivos e mediadores destas relações e dos próprios sujeitos, simultaneamente. Desse modo, as interações humanas são cruciais para a constituição dos sujeitos e para o desenvolvimento de seus sistemas psicológicos.

$\mathrm{Na}$ situação escolar analisada, educadora-pesquisadora e educandos constituem um grupo de agentes construtores de conhecimento. Para além da relação educador-educando-conteúdo, existe também uma relação de convivência por meio do ensino-aprendizagem dos conteúdos cotidianos, que somente são possíveis por meio da interação.

$\mathrm{Na}$ situação analisada, é importante ressaltar que a forma com que a educadora guia a atividade proposta interfere diretamente no envolvimento das crianças, pois ela os considera agentes capazes de interagir e construir conjuntamente conhecimento, em vez de simplesmente serem receptores dele. Deste modo, a agência, na situação analisada, é ferramenta-e-resultado fundamental do processo educativo.

No excerto analisado, as crianças apresentaram a maior parte dos turnos, dado que em si é relevante para evidenciar a agência dos educandos. Os turnos da educadora-pesquisadora, por sua vez, foram promotores da reflexão crítica, possibilitando que os educandos chegassem as suas próprias conclusões a partir dos significados e sentidos compartilhados em grupo. Nota-se que o envolvimento se amplia conforme suas possibilidades de agência na atividade escolar.

A experiência empírica da educadora-pesquisadora revela que, quando os educandos são colocados em uma posição de meros receptores das informações, eles perdem o interesse e concentração, movimentando-se pela sala, procurando outras coisas para fazer que não seja se engajar na proposta. No entanto, quando são agentes do próprio processo de ensino-aprendizagem mostram-se entusiasmados, 
muitas vezes falando alto, interrompendo uns aos outros ou tocando os objetos disponibilizados impulsivamente, com evidente desejo de participar.

Leontiev (2016), ao analisar o desenvolvimento da psiquê infantil, destaca o papel fundamental da agência no processo de ensino-aprendizagem, de modo que, para o autor, a agência pode servir como ferramenta para o desenvolvimento de funções psicológicas mais desenvolvidas: "A mudança do lugar ocupado pela criança no sistema das relações sociais é a primeira coisa que precisa ser notada quando se tenta encontrar uma resposta ao problema das forças condutoras do desenvolvimento da sua psique" (LEONTIEV, 1944/2016, p. 63).

O autor explica que, para entender o sistema psicológico infantil, é preciso entender suas realidades para além de como as crianças interagem em suas atividades reais e em suas condições concretas de vida. Adicionalmente, constata como é a atividade da criança em desenvolvimento e em interação que forma sua consciência. Dessa maneira, concebe-se que, em suas atividades reais (combinar elementos sobre o brincar), sob condições concretas (de forma compartilhada e não imposta), as crianças interagem e desenvolvem suas consciências:

Ao estudar o desenvolvimento da psique infantil, nós devemos, por isso, começar analisando o desenvolvimento da atividade da criança, como ela é construída nas condições concretas de vida. Só com este modo de estudo pode-se elucidar o papel tanto das condições externas de sua vida, como das potencialidades que ela possui. Só com este modo de estudo, baseado na análise do conteúdo da própria atividade infantil em desenvolvimento, é que podemos compreender de forma adequada o papel condutor da educação e da criação, operando precisamente em sua atividade e em sua atitude diante da realidade, e determinando, portanto, sua psique e sua consciência (LEONTIEV, 1944/2016, p. 63).

Partindo do pressuposto que as crianças aprendem e se desenvolvem a partir de suas experiências reais de vida, em interação com o mundo e com os demais sujeitos de seu entorno, pode-se compreender que a atividade descrita no excerto permite maiores oportunidades de aprendizagem e de desenvolvimento. Além disso, quando o sujeito participa ativamente de uma construção coletiva, relaciona-se com ela emocionalmente em diferentes escalas do que se relacionaria com um conhecimento apresentado.

Para Vygotsky (1934/2009), é por meio das relações reais entre as pessoas que as funções psicológicas superiores se internalizam e se desenvolvem. Nesse 
pensamento, a subjetividade é constituída por e possibilitada pelas relações sociais, no processo de internalização de processos que são, inicialmente, interpsicológicos. No excerto analisado para o desenvolvimento deste artigo, observa-se o processo de mecanismos sócio-culturais sendo, aos poucos, internalizado pelas crianças, ampliando os repertórios linguísticos. Para o autor, a emoção também é um elemento fundamental nas relações humanas. A emoção na visão vygotskiana funciona como um filtro de apreensão da realidade por parte do sujeito, unindo fatores externos (contextuais) e internos (no desenvolvimento da subjetividade dos sujeitos), ao mesmo tempo em que serve de base para o desenvolvimento de funções psicológicas superiores. Compreender a importância da interação e da emoção nesta perspectiva é fundamental para entender a relevância desta pesquisa empírica para a academia.

\section{Considerações finais}

$\mathrm{Na}$ vivência escolar analisada neste artigo, a educadora-pesquisadora intencionalmente propôs uma atividade que despertasse emoção nas crianças, tendo o brincar e a agência como ferramentas, estreitando, desta maneira, os vínculos afetivos e impulsionando o desenvolvimento de todos os educandos.

Conforme apresentado, é sabido que as emoções e os sentimentos devem ser considerados dentro do contexto escolar. Freire (1996/2015) pondera que a agência do educador no processo de ensino-aprendizagem é de fundamental importância, uma vez que ele deixa de apresentar seus conhecimentos prévios, adquiridos ao longo de sua história por sua participação na sociedade e na cultura, e se permite construir novos saberes, a partir da interação com os outros sujeitos de seu contexto; neste caso, os educandos, carregados de experiências próprias, ainda que mais escassas em termos de tempo e historicidade.

Este artigo visou a apresentar a relevância da emoção para o ensinoaprendizagem partindo de uma perspectiva histórico-cultural. Para isso, ressaltou aspectos inerentes ao contexto escolar que são fundamentais para o desenvolvimento infantil: o brincar e a agência. 
Os dados da pesquisa mostraram o aumento de interesse e de aproveitamento nas atividades cuja abordagem possibilitou a interação e a construção conjunta do conhecimento. Uma vez considerados agentes ativos na construção do próprio conhecimento, a natureza da relação entre educador e educando muda, deixando de ser unilateral, de ter caráter transmissivo e informativo; torna-se uma relação de respeito mútuo e democrática, em que sentidos e significados são partilhados e negociados. Essa mudança na abordagem escolar caracteriza uma transformação da relação entre os sujeitos, possibilitando o estabelecimento e estreitamento de vínculos afetivos, de modo a produzir vivências emocionais mais intensas e promotoras de desenvolvimento.

Assim, este artigo possibilita ressaltar o fato de que é possível impulsionar o desenvolvimento infantil em todas suas potencialidades (social, cognitiva, afetiva e motora), priorizando a agência dos educandos, pois, desta forma, serão promovidas emoções agradáveis e serão agregadas possibilidades de que os estudantes possam se conhecer no processo de aprendizagem. Além disso, é crucial que, na interação, o educador participe das brincadeiras, estabelecendo e estreitando os vínculos afetivos com seus educandos para alcançar suas maiores potencialidades para um processo de ensino-aprendizagem que objetiva o desenvolvimento.

\section{Referências}

AHEARN, L. M. Language and Agency. Annual Reviews Anthropol. v.30, p. 109137, 2001.

ALMEIDA, L. R. Ser Professor: um diálogo com Henri Wallon. In: MAHONEY, A. Alvarenga; ALMEIDA, L. R. (org.). A constituição da pessoa na proposta de Henri Wallon. São Paulo: Edições Loyola, 2004.

BAKHTIN, M.; VOLOSHÍNOV, V. N. Marxismo e filosofia da linguagem. Trad. de Michel Lahud e Yara Frateschi Vieira. São Paulo: Hucitec, 1929/1981.

BRANDÃO, C. R., BORGES, M. C. A pesquisa participante: um momento da educação popular. Uberlândia: Rev. Ed. Popular, v. 6, p.51-62. jan./dez, 2007. 
CORSARO, W. Peer Culture. In: QVORTRUP, J.; CORSARO, W. A.; HONIG, MS. The Palgrave Handbook of Childhood Studies. Hampshire/New York: Palgrave Macmillan, 2009, p.301 - 315.

FREIRE, P. Pedagogia da Autonomia. São Paulo: Paz e Terra, 1996/2015.

JAMES, A. Agency. In: QVORTRUP, J.; CORSARO, W. A.; HONIG, M-S. The Palgrave Handbook of Childhood Studies. Hampshire/New York: Palgrave Macmillan, 2009.

LEITE, D. M. Educação e Relações Interpessoais. In: PATTO, M. H. S. (org.) Introdução à Psicologia Escolar. São Paulo: T.A. Queiroz Editor, 1986.

LEITE, S. A. S; TASSONI, E. C. M. Afetividade no processo de ensinoaprendizagem: as contribuições da teoria walloniana. Educação, v. 36, n. 2, 2013, p. 262-271.

LEONTIEV, A. N. Uma contribuição à teoria do desenvolvimento da psique infantil. In: VIGOTSKII, L. S.; LURIA, A. R.; LEONTIEV, A. N. (org.) Linguagem, desenvolvimento e aprendizagem. São Paulo: Ícone, 1944/2016. p. 59-84.

MARX, K. Theses on Feuerbach. Marx/Engels Selected Works, Volume One, p. 13 - 15.Progress Publishers, Moscow, USSR, 1845/1969. Disponível em: https://www.marxists.org/archive/marx/works/1845/theses/theses.htm. Acesso em $05 / 12 / 2016$

MARX, K.; ENGELS, F. A ideologia Alemã. Expressão Popular: São Paulo, $1845 / 2009$.

VOLOSHÍNOV, V. N. Marxism and the Philosophy of Language, Seminar Press, in liaison with the Harvard University Press and the Academic Press Inc., 1929/1973. Disponível em https://www.marxists.org/archive/voloshinov/1929/marxism-language.htm acesso em 07 de 09, 2016.

VYGOTSKY, L. S. Psicologia Pedagógica. São Paulo: Martins Fontes, 1926/2010.

The Problem of the Cultural Development of the Child. Journal of Genetic Psychology, vol. 36, p.415-32, 1929/1994. Disponível em https://www.marxists.org/archive/vygotsky/works/1929/cultural_development.ht m Acesso em 29/09/2016.

VYGOTSKY, L. S. Imaginación y creación em la edad infantil. Tradução de Francisco Martinez, 2.Ed. Moscou - Leningrado: GIZ, 1930 /1999. 
Marxists.org.

The Genesis of Higher Mental Functions. Lev Vygotsky Archive: https://www.marxists.org/archive/vygotsky/works/1931/higher-mentalfunctions.htm Acesso em 05/07/2017.

A Formação Social da Mente: O Desenvolvimento dos Processos Psicológicos Superiores. São Paulo: Martins Fontes, 1933-1935/2009.

Pensamento e Linguagem. Tradução de Jefferson Luiz Camargo. São Paulo: Martins Fontes, 1934/2008.

$1935 \mathrm{a} / 1994$.

Foundations of Paedology. Leningrad: Izdanie Instituta, https://www.marxists.org/archive/vygotsky/works/1934/environment.htm . Acesso em 15/10/2018

Disponível The Problem of Environment. The Vygotsky Reader, 1935b/1994. https://www.marxists.org/archive/vygotsky/works/1934/environment.htm . Acesso em $15 / 10 / 2018$

VYGOTSKY, L. S. The Collected Works of Vygotsky - Child Psychology. US: Springer, 1998. v. 